\title{
Variability of within-breath reactance in COPD patients and its association with dyspnoea
}

\author{
Bernt B. Aarli ${ }^{1,2}$, Peter M.A. Calverley ${ }^{3}$, Robert L. Jensen ${ }^{4}$, Tomas M.L. Eagan ${ }^{1,2}$, \\ Per S. Bakke ${ }^{1}$ and Jon A. Hardie ${ }^{1}$ \\ Affiliations: \\ ${ }^{1}$ Institute of Clinical Science, University of Bergen, Bergen, Norway. \\ ${ }^{2}$ Dept of Thoracic Medicine, Haukeland University Hospital, Bergen, Norway. \\ ${ }^{3}$ Clinical Science Centre, University Hospital Aintree, Liverpool, UK. \\ ${ }^{4}$ LDS Hospital, Pulmonary Division, Salt Lake City, UT, USA.
}

Correspondence: Bernt B. Aarli, Institute of Clinical Science, University of Bergen, Pb 7800, 5020 Bergen, Norway. E-mail: bernt.aarliak2.uib.no

ABSTRACT The forced oscillation technique can identify expiratory flow limitation (EFL) when a large difference in inspiratory and expiratory reactance $(\Delta X \mathrm{rs})$ occurs. However, flow limitation can vary from breath to breath, and so we compared a multiple-breath $\Delta X$ rs approach to the traditional breath-by-breath assessment of EFL. We investigated the within- and between-day reproducibility and the factors that affect the size of $\Delta X \mathrm{rs}$ when used as a continuous measurement over multiple breaths. In addition, we examined how multiple-breath $\Delta X$ rs relates to the sensation of breathlessness.

425 moderate to very severe chronic obstructive pulmonary disease (COPD) patients and 229 controls were included. Spirometry and impedance measurements were performed on a MasterScope CT Impulse Oscillation System.

Median $\Delta X_{\mathrm{rs}}$ approached zero in healthy controls with little variation between measurements. COPD patients generally had higher $\Delta X \mathrm{rs}$ and higher variability. The COPD patients with $\Delta X \mathrm{rs}>0.1 \mathrm{kPa} \cdot \mathrm{L}^{-1} \cdot \mathrm{s}^{-1}$ were prone to be more breathless and had a higher modified Medical Research Council dyspnoea scale score. In controls, the 95 th percentile of $\Delta X$ rs was as low as $0.07 \mathrm{kPa} \cdot \mathrm{L}^{-1} \cdot \mathrm{s}^{-1}$.

We describe a new method to assess EFL at a patient level and propose a cut-off, mean $\Delta X_{\mathrm{rs}}$ $>0.1 \mathrm{kPa} \cdot \mathrm{L}^{-1} \cdot \mathrm{s}^{-1}$, as a way to identify COPD patients who are more likely to report dyspnoea.

@ERSpublications

Within-breath reactance in COPD correlates with dyspnoea and adds information beyond that of spirometry alone http://ow.ly/CvYOT

This article has been revised according to the erratum published in the January 2017 issue of the European Respiratory Journal.

This article has supplementary material available from erj.ersjournals.com

Received: March 172014 | Accepted after revision: Sept 212014 | First published online: Oct 302014

Conflict of interest: None declared.

Copyright OERS 2015 


\section{Introduction}

The hallmark of chronic obstructive pulmonary disease (COPD) is the presence of expiratory flow limitation (EFL) during a forced expiratory manoeuvre [1], and as the disease progresses, EFL is frequently present during resting tidal breathing [2]. In these circumstances, expiratory flow cannot increase, irrespective of the activity of the expiratory muscles [3,4]. Greater expiratory flow can only be achieved by increasing the operating lung volume, shifting end-expiratory lung volume towards the total lung capacity [5]. Hyperinflation of the lungs may improve airflow, but it comes at the cost of increased inspiratory work and may also impair inspiratory muscle function [6]. These mechanical properties of breathing are thought to contribute to the sensation of dyspnoea [7,8], and some have suggested that the occurrence of EFL during tidal breathing is a better indicator of dyspnoea than spirometric measurement [9].

Although a number of techniques has been designed to identify tidal EFL, it is not routinely measured in clinical practice $[2,10-13]$. Disadvantages in many of these techniques preventing more widespread use are that they are invasive, time-consuming, technically demanding, use bulky equipment or they need post-test analysis, such as visual inspection of flow/volume curves.

Tidal EFL can be detected by the forced oscillation technique (FOT) [14, 15]. In patients with EFL, collapse of peripheral airways in expiration prevents the oscillatory pressure signal from reaching the alveoli. Instead, it is reflected from the stiffer airway walls proximal to the site of obstruction, resulting in a pronounced decrease in the expiratory reactance with a widening of the within-breath reactance difference $(\Delta X \mathrm{rs})$. A similar negative spike in reactance occurs normally at very low lung volumes approaching closing volume [16]. FOT uses an empirically defined cut-off in $\Delta X_{\mathrm{r}}$ to define whether an individual breath is flow limited, thereby simplifying interpretation and eliminating observer bias $[14,15]$. While this method accurately defines EFL on an individual breath, there is evidence that flow limitation varies between breaths, possibly reflecting spontaneous fluctuation in end-expiratory lung volume [14]. To date, we lack data from large numbers of patients examining the individual reproducibility of a patient-based measure of EFL over time and considering how such an index relates to clinical outcomes.

We addressed this issue by examining data collected as part of large, multicentre, prospective trial (Evaluation of COPD Longitudinally to Identify Predictive Surrogate Endpoints (ECLIPSE)) with additional patients recruited from our clinical catchment area [17]. Multiple previous publications have come from the total ECLIPSE dataset, including a report of the overall oscillatory mechanics data [18]. However, no previous analysis of partitioned oscillatory mechanics has been presented.

We propose that averaging $\Delta X$ rs over multiple breaths will reduce variability associated with a single breath assessment of the patient's flow limitation status. This is somewhat different from the previously described breath-by-breath EFL definition, but represents a longer timeframe that is in line with the current European Respiratory Society (ERS) task force recommendations of FOT measurements. To evaluate our multiple-breath $\Delta X_{\mathrm{rs}}$ approach, we explored measurement properties of this way of evaluating EFL in COPD patients and controls. We looked at within- and between-day reproducibility, and at factors affecting size of multiple-breath $\Delta X$ rs. In addition, we examined how the intensity of breathlessness relates to multiple-breath $\Delta X$ rs-defined EFL.

\section{Methods}

\section{Study population}

The ECLIPSE study was a 3-year, observational, case-control study performed between 2006 and 2010 . Design and entry criteria of the ECLIPSE study have previously been described [17]. Our site, Haukeland University Hospital, Bergen, Norway, contributed 400 COPD patients and 147 smoking controls. Initially, we had no nonsmoking controls; therefore, an additional 46 nonsmoking and 36 smoking controls were added, as well as 25 COPD patients. All additional study subjects met the ECLIPSE entry criteria but were not called in at all visits; the nonsmoking controls completed baseline assessment only. In brief, test subjects (age 40-74 years) consisted of 425 stable COPD patients (post-bronchodilator forced expiratory volume in $1 \mathrm{~s}\left(\mathrm{FEV}_{1}\right)<80 \%$ predicted, $\mathrm{FEV}_{1} /$ forced vital capacity $(\mathrm{FVC})$ ratio $<70 \%$ and a smoking history $\geqslant 10$ pack-years), 183 smoking controls (FEV $1>85 \%$ pred, FEV $1 / F V C>70 \%$ and $\geqslant 10$ pack-years) and 46 nonsmoking controls (FEV1 $>85 \%$ pred, $\mathrm{FEV}_{1} / \mathrm{FVC}>70 \%$ and $<1$ pack-year). The controls had no other significant diseases identified. All participants received written and oral information prior to inclusion, and signed informed consent was retrieved.

\section{Data collection}

Participants attended the centre on eight occasions: baseline, 3 and 6 months, then half-yearly for a total of 3 years. Stable COPD was the target of the study. If a COPD patient had ongoing exacerbation at the time of a visit, the visit was rescheduled. In the clinic, breathlessness was assessed using the modified Medical Research Council (mMRC) dyspnoea scale score. As a measure of health impairment, the 
St George's Respiratory Questionnaire for COPD patients (SGRQ-C) was used [19]. Use of medication was noted. Blood gases were analysed and 6-min walking test (6MWT) performed according to American Thoracic Society guidelines [20]. We report arterial oxygen partial pressure and 6-min walking distance from the baseline visit. Results from the 6MWT in the ECLIPSE study have previously been published [21].

\section{Pulmonary function tests}

Both pre- and post-bronchodilator measurements of spirometry and FOT were carried out at each visit using a MasterScope CT Impulse Oscillation System (IOS) (Jaeger, Hoechberg, Germany). In this article, only the post-bronchodilator measurements are described and $\mathrm{FEV}_{1} \%$ pred was determined using local reference values [22]. Whole-body plethysmography measurement of lung volume and its subdivisions was made at baseline, and visits 4, 6, and 8. All pulmonary function tests met international standards [23-25]. Pulmonary impedance (FOT) was measured with the subject seated, with their cheeks supported and wearing a nose clip. Each subject performed three acceptable IOS measurements over $30 \mathrm{~s}$ of tidal-volume breathing. Acceptability was determined on site by the technician in accordance with the criteria proposed by the 2003 ERS task force [24]. This involved visual inspection of the patient while performing the measurements and a review of the flow impedance tracings. We report both whole-breath and partitioned (inspiratory and expiratory) values for the following parameters: resistance at $5 \mathrm{~Hz}\left(\mathrm{Rrs}_{5}\right)$, reactance at $5 \mathrm{~Hz}$ $\left(R \mathrm{rs}_{5}\right)$ and the resonant frequency ( $f_{\mathrm{res}}$ ). In addition, we report $\Delta X \mathrm{rs}$ calculated as the mean $X_{\mathrm{rs}_{5}}$ during inspiration minus the mean $X_{\mathrm{rs}_{5}}$ during expiration averaged over the sampling period, a multiple-breath approach. A subsequent version of the JLAB software (version 5.22; VIASYS Healthcare GmbH, Hoechberg, Germany) calculates a breath-by-breath difference in inspiratory minus expiratory $\mathrm{Xrs}_{5}$, which is then averaged over the sampling period. Agreement between our multiple-breath $\Delta X \mathrm{rs}$ and the breath-by-breath $\Delta X$ rs was tested by recalculating 50 of our measurements selected at increasing levels of $\Delta X \mathrm{rs}$ in an upgrade of the IOS software, JLAB 5.22 (fig. 1).

\section{Data analyses}

Results are shown as mean or median and standard deviation or interquartile range. SPSS Statistics (version 20; IBM, Armonk, NY, USA) was used for statistical analysis. To evaluate the compatibility between multiple-breath and breath-by-breath $\Delta X \mathrm{rs}$ measurements, the intraclass correlation coefficient (ICC) was calculated. Assessment of repeatability was performed using the coefficient of variation for $R_{\mathrm{rs}_{5}}$

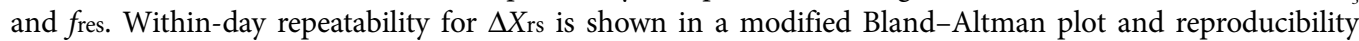
over time in a timeline plot over the eight-visit/3-year period for smoking controls and COPD patients.

Receiver operating characteristic (ROC) curves were used to illustrate the ability of $\Delta X_{\mathrm{rs}}$ and FEV 1 to discriminate dyspnoea at various thresholds. A binary classifier was created from the mMRC dyspnoea scale score using a cut-off at $\geqslant 2$, in line with the empirical clinical threshold suggested in the recent update of the Global Initiative for Chronic Obstructive Lung Disease (GOLD) report [1]. Correlation between the $\Delta X$ rs variables was tested by Spearman's rank correlation coefficient.

FIGURE 1 Analysis of reactance difference $\left(\Delta X_{\mathrm{rs}}\right)$ measured by subtracting expiratory from inspiratory reactance from multiple breaths on the vertical axis versus the averaged breath-by-breath measurements on the horizontal axis. Intraclass correlation coefficient: 0.983 .

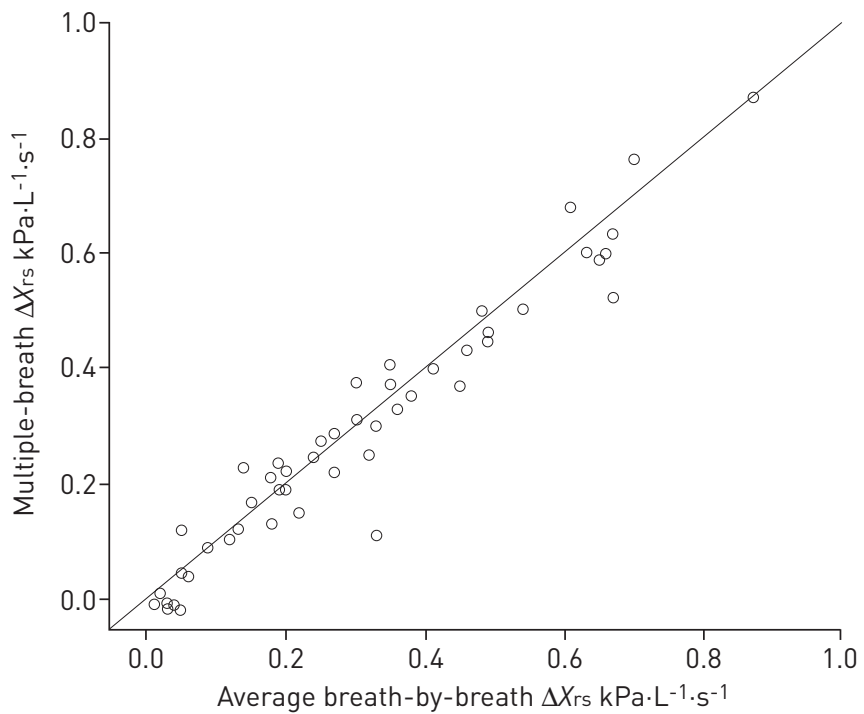




\section{Results}

\section{Baseline characteristics}

Baseline characteristics of the healthy subjects and COPD patients are shown in table 1 . The mean FEV1 in the 229 healthy subjects was $3.4 \mathrm{~L}$ (97\% pred). The COPD patients ranged from moderate to very severe: FEV1 42\%, 44\%, and 14\% pred in GOLD grades 2-4, respectively. Cases and controls were well matched for height. COPD patients were lighter, particularly those with very severe disease. The healthy smokers were significantly younger than the COPD patients $(\mathrm{p}<0.001)$, while healthy nonsmokers were not significantly different (table 1). Healthy subjects reported little dyspnoea on the mMRC scale and had median SGRQ-C within the normal range. Indices of pulmonary hyperinflation worsened across the GOLD grades while mean arterial oxygen tension fell from $10.8 \mathrm{kPa}$ in the controls to $8.6 \mathrm{kPa}$ in COPD patients with severe disease.

\section{Validation of multiple-breath $\Delta X_{\text {rs }}$ methodology}

Figure 1 presents the mean of a 30-s multiple-breath $\Delta X_{\mathrm{rs}}$ analysis plotted against a recalculated breath-by-breath measurement from the same sampling period from 50 measurements from our sample chosen in ascending order. The ICC was 0.983 and there was no evidence of an effect of baseline value on the degree of agreement.

\section{Baseline respiratory impedance data}

Table 2 summarises the impedance measurements. Controls had a median $R \mathrm{rs}_{5}$ of $0.29 \mathrm{kPa} \cdot \mathrm{L}^{-1} \cdot \mathrm{s}^{-1}$, median $R \mathrm{rs}_{5}$ of $-0.08 \mathrm{kPa} \cdot \mathrm{L}^{-1} \cdot \mathrm{s}^{-1}$ and median $f_{\text {res }}$ of $11.7 \mathrm{~Hz}$, with little variation between inspiratory and expiratory measurements, and $\Delta X \mathrm{rs}$ close to zero with a 95th percentile $<0.07 \mathrm{kPa} \cdot \mathrm{L}^{-1} \cdot \mathrm{s}^{-1}$. In COPD patients, median $R_{r_{5}}$ ranged from 0.42 to $0.49 \mathrm{kPa} \cdot \mathrm{L}^{-1} \cdot \mathrm{s}^{-1}$ across the GOLD grades, median $\operatorname{Rrs}_{5}$ from -0.15 to $-0.40 \mathrm{kPa} \cdot \mathrm{L}^{-1} \cdot \mathrm{s}^{-1}$ and median fres from 17.2 to $23.6 \mathrm{~Hz}$. For our target FOT parameter $\Delta X \mathrm{rs}$, the median was $0.04 \mathrm{kPa} \cdot \mathrm{L}^{-1} \cdot \mathrm{s}^{-1}$ in GOLD grade $2,0.11 \mathrm{kPa} \cdot \mathrm{L}^{-1} \cdot \mathrm{s}^{-1}$ in GOLD grade 3 and $0.26 \mathrm{kPa} \cdot \mathrm{L}^{-1} \cdot \mathrm{s}^{-1}$ in GOLD grade 4 . The mean individual coefficient of variation for $\operatorname{Rrs}_{5}$ and fres ranged from $4.0 \%$ to $6.4 \%$, which is acceptable by ERS recommendations [24].

\section{TABLE 1 Baseline characteristics}

\begin{tabular}{|c|c|c|c|c|c|}
\hline & \multicolumn{2}{|c|}{ Controls } & \multicolumn{3}{|c|}{ COPD } \\
\hline & Nonsmoking & Smoking & GOLD 2 & GOLD 3 & GOLD 4 \\
\hline Subjects $\mathrm{n}$ & 46 & 183 & 179 & 186 & 60 \\
\hline Age years & $61 \pm 8$ & $53 \pm 8$ & $62 \pm 7$ & $64 \pm 7$ & $64 \pm 6$ \\
\hline Height $\mathrm{cm}$ & $173 \pm 9$ & $172 \pm 9$ & $171 \pm 8$ & $170 \pm 9$ & $171 \pm 8$ \\
\hline Weight kg & $78 \pm 13$ & $78 \pm 14$ & $76 \pm 18$ & $74 \pm 18$ & $69 \pm 19$ \\
\hline BMI $\mathrm{kg} \cdot \mathrm{m}^{-2}$ & $26 \pm 3$ & $26 \pm 4$ & $26 \pm 5$ & $25 \pm 5$ & $24 \pm 5$ \\
\hline $\begin{array}{l}\text { Smoking pack-years } \\
\text { median (IQR) }\end{array}$ & & $27(17-39)$ & $35(23-50)$ & $37(24-50)$ & $38(25-55)$ \\
\hline $\mathrm{PaO}_{2}{ }^{\#} \mathrm{KPa}$ & $10.7 \pm 1.1$ & $10.8 \pm 1.2$ & $9.6 \pm 1.1$ & $9.2 \pm 1.0$ & $8.6 \pm 1.1$ \\
\hline 6MWD" $\mathrm{m}$ & & & $462 \pm 93$ & $414 \pm 105$ & $338 \pm 128$ \\
\hline \multicolumn{6}{|l|}{ Symptoms mean (IQR) } \\
\hline $\begin{array}{l}\text { mMRC\# dyspnoea scale } \\
\text { score }\end{array}$ & $0.1(0-0)$ & $0.2(0-0)$ & $1.1(0-2)$ & $1.7(1-2)$ & $2.3(1.75-3)$ \\
\hline SGRQ-C $C^{\#}$ score & $3(0-5)$ & $5(2-9)$ & $34(19-51)$ & $44(30-59)$ & $56(49-68)$ \\
\hline \multicolumn{6}{|l|}{ Spirometry } \\
\hline FEV $1 \mathrm{~L}$ & $3.3 \pm 0.7$ & $3.4 \pm 0.7$ & $1.9 \pm 0.4$ & $1.3 \pm 0.3$ & $0.8 \pm 0.2$ \\
\hline $\mathrm{FEV}_{1} \%$ pred & $100 \pm 10$ & $97 \pm 9$ & $60 \pm 6$ & $40 \pm 5$ & $25 \pm 4$ \\
\hline FVC L & $4.1 \pm 0.9$ & $4.4 \pm 0.9$ & $3.6 \pm 0.9$ & $3.2 \pm 0.9$ & $2.6 \pm 0.8$ \\
\hline \multicolumn{6}{|l|}{ Plethysmography } \\
\hline $\mathrm{TLC}^{\#} \mathrm{~L}$ & $6.5 \pm 1.3$ & $6.5 \pm 1.3$ & $7.0 \pm 1.4$ & $7.2 \pm 1.4$ & $7.8 \pm 1.3$ \\
\hline$I C^{\#} \mathrm{~L}$ & $3.3 \pm 0.8$ & $3.3 \pm 0.8$ & $2.8 \pm 0.8$ & $2.4 \pm 0.7$ & $2.0 \pm 0.6$ \\
\hline $\mathrm{RV}^{\#} \mathrm{~L}$ & $2.1 \pm 0.5$ & $1.8 \pm 0.6$ & $2.8 \pm 0.9$ & $3.4 \pm 0.9$ & $4.5 \pm 1.0$ \\
\hline
\end{tabular}

Data are presented as mean $\pm S D$, unless otherwise stated. $n=654$. COPD: chronic obstructive pulmonary disease; GOLD: Global Initiative for Chronic Obstructive Lung Disease; BMI: body mass index; IQR: interquartile range; $\mathrm{PaO}_{2}$ : arterial oxygen tension; 6MWD: 6-min walking distance; mMRC: modified Medical Research Council; SGRQ-C: St George's Respiratory Questionnaire for COPD patients; FEV1: forced expiratory volume in $1 \mathrm{~s}$; FVC: forced vital capacity; TLC: total lung capacity; IC: inspiratory capacity; RV: residual volume. ${ }^{\#}$ : analysis restricted to patients with complete data. 
TABLE 2 Pulmonary impedance measurements at baseline

\begin{tabular}{|c|c|c|c|c|c|c|}
\hline & \multicolumn{2}{|c|}{ Controls } & \multicolumn{3}{|c|}{ COPD } & $\mathrm{CV}^{\#} \%$ \\
\hline Subjects $\mathbf{n}$ & 46 & 183 & 179 & 186 & 60 & \\
\hline Insp & $0.27(0.47)$ & $0.27(0.43)$ & $0.37(0.57)$ & $0.42(0.63)$ & $0.45(0.60)$ & 5.8 \\
\hline Exp & $0.30(0.53)$ & $0.31(0.52)$ & $0.44(0.70)$ & $0.47(0.75)$ & $0.47(0.78)$ & 6.4 \\
\hline $\mathrm{Xrs}_{5} \mathrm{kPa} \cdot \mathrm{L}^{-1} \cdot \mathrm{s}^{-1}$ median (fifth percentile) & $-0.07(-0.16)$ & $-0.08(-0.18)$ & $-0.15(-0.42)$ & $-0.26(-0.54)$ & $-0.40(-0.66)$ & \\
\hline$\Delta X \mathrm{rs} \mathrm{KPa} \cdot \mathrm{L}^{-1} \cdot \mathrm{s}^{-1}$ & $-0.01(0.04)$ & $-0.01(0.07)$ & $0.04(0.37)$ & $0.11(0.51)$ & $0.26(0.66)$ & \\
\hline fres $\mathrm{Hz}$ & $12.0(16.0)$ & $11.5(16.4)$ & $17.2(24.8)$ & $20.0(27.5)$ & $23.6(31.2)$ & 4.0 \\
\hline Insp & $10.9(15.1)$ & $10.3(15.5)$ & $16.5(22.4)$ & $18.8(25.7)$ & $21.5(29.8)$ & 4.1 \\
\hline Exp & $12.3(17.9)$ & $12.3(17.8)$ & 17.7 (26.5) & $20.4(28.4)$ & 24.4 (31.2) & 5.1 \\
\hline
\end{tabular}

Data are presented as median (95th percentile) unless otherwise stated. $\mathrm{n}=654$. COPD: chronic obstructive pulmonary disease; GOLD: Global Initiative for Chronic Obstructive Lung Disease; CV: coefficient of variation; Rrs : resistance at $5 \mathrm{~Hz}$; Insp: inspiratory; Exp: expiratory; Rrs5: reactance at $5 \mathrm{~Hz} ; \Delta X_{\mathrm{rs}}$ : difference between Insp and Exp values of $R_{\mathrm{rs}_{5}}$; fres: resonant frequency. ${ }^{\#}$ : mean over three measurements.

Stability of patient-level $\Delta X_{r}$ classification at baseline and over time

At baseline, controls had mean $\Delta X \mathrm{rs}$ values clustered around zero (fig. 2a). A somewhat higher individual standard deviation was found in smoking than in nonsmoking controls. The COPD patients had considerably higher $\Delta X$ rs variability at baseline, both for mean values and individual standard deviation, and a higher variability was found with increasing severity of disease. Patients with $\Delta X \mathrm{rs}>0.1 \mathrm{kPa} \cdot \mathrm{L}^{-1} \cdot \mathrm{s}^{-1}$ in GOLD grades 2 and 3 had a significant higher use of $\beta_{2}$-agonists; in GOLD grade 3 , the use of theophylline was also significantly higher between the groups (online supplementary material). Mean $\Delta X_{\mathrm{rs}}$ in smoking controls was plotted over time (fig. 2b). $\Delta X_{\mathrm{rs}}$ measurements in controls remained low over time. 17 controls showed less stability by crossing the threshold $\Delta X \mathrm{rs}$ of $0.1 \mathrm{kPa} \cdot \mathrm{L}^{-1} \cdot \mathrm{s}^{-1}$ on one or more of the visits. In this group with abnormal $\Delta X \mathrm{rs}$, significantly higher mean body mass index (BMI) was found than among the rest of the controls (30 versus $\left.26 \mathrm{~kg} \cdot \mathrm{m}^{-2}, \mathrm{p}<0.001\right)$. Though many COPD patients had $\Delta X_{\mathrm{rs}}$ measurements comparable to those of the smoking controls, high values were common and those with high values tended to continue to have high values over time (fig. $2 \mathrm{c}$ ).

\section{Relationship of $\triangle X$ rs with baseline characteristics in the whole population and among COPD} patients

$\Delta X$ rs correlated with most parameters, but not sex; consequently, we report our results pooled, with men and women combined (table 3). The age correlation was considered to be an effect of selection bias, as the
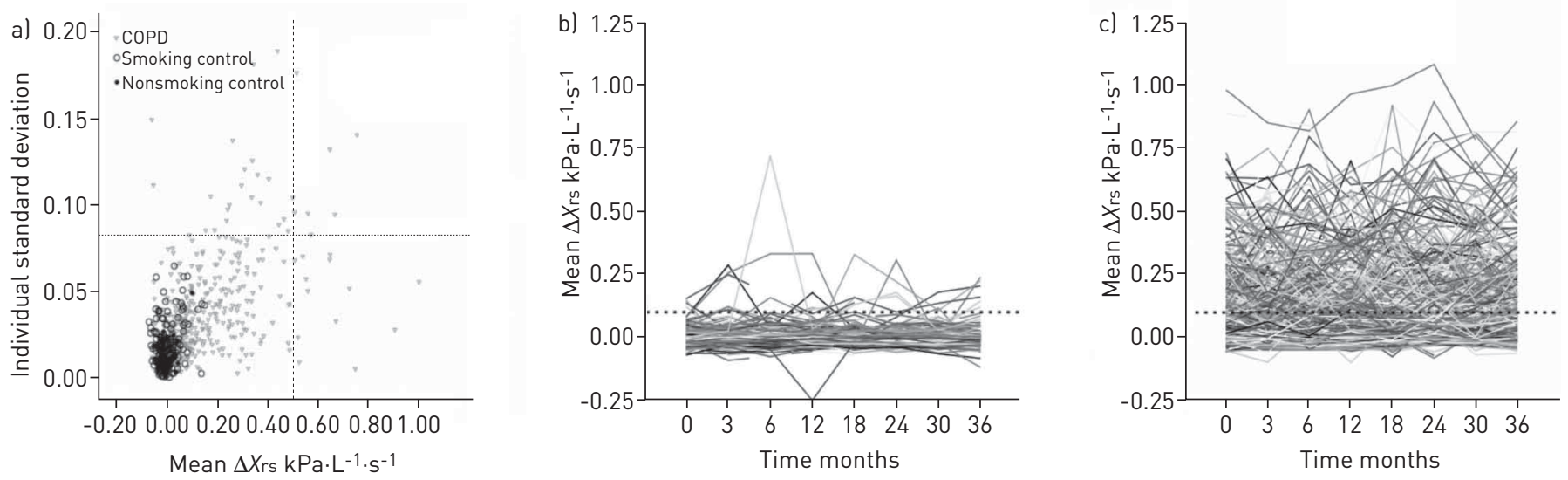

FIGURE 2 Repeatability and reproducibility. a) Individual standard deviation of three measurements of reactance difference ( $\left.\Delta X_{\mathrm{rs}}\right)$ compared with mean $\Delta X_{\mathrm{rs}}$ in chronic obstructive pulmonary disease (COPD) patients and controls at baseline. The vertical, dashed lines represents the 95 th percentile of $\Delta X_{\mathrm{rs}}$ among COPD

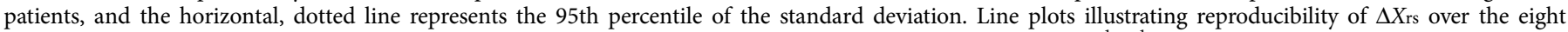
visits/3 years in b) smoking controls $(n=183)$ and c) COPD patients $(n=425)$. The dotted line is set at $0.1 \mathrm{kPa} \cdot \mathrm{L}^{-1} \cdot \mathrm{s}^{-1}$. 
smoking controls were younger than the COPD patients and because no such correlation was found when compared with the more closely matched nonsmoking controls.

The strongest relationship was seen with the spirometric variables, especially FEV1, although significant associations were seen in the COPD patients with walking distance and health status. BMI showed a stronger association with $\Delta X_{\mathrm{rs}}$ in the COPD patients than the group as a whole. The relationship between the distribution of $\Delta X_{\mathrm{rs}}$ and deciles of $\mathrm{FEV}_{1} \%$ pred is shown in figure $3 \mathrm{a}$ and $\mathrm{b}$, and the relationships between baseline $\Delta X_{\mathrm{rs}}$ and $\mathrm{FEV} 1 / \mathrm{FVC}$ and inspiratory capacity (IC)/total lung capacity (TLC) ratio in cases and controls are shown in figure $3 \mathrm{c}$ and $\mathrm{d}$. In COPD patients, considerable variation was seen in the mean $\Delta X_{\mathrm{rs}}$ within any FEV1 stratum, although the group median $\Delta X_{\mathrm{rs}}$ increased as $\mathrm{FEV}_{1} \%$ pred declined (fig. 3a). In healthy controls (fig. 3b), $\Delta X$ rs measurements exceeding $0.1 \mathrm{kPa} \cdot \mathrm{L}^{-1} \cdot \mathrm{s}^{-1}$ were very rare. Similar variability was seen when data were expressed relative to lung volumes and FEV1/FVC, with many individuals having low ratios (fig. 3d) and low IC/TLC values still not exhibiting flow limitation over multiple breaths (fig. 3c).

\section{Physiological predictors of breathlessness}

The threshold value for breathlessness, $\Delta X \mathrm{rs} 0.1 \mathrm{kPa} \cdot \mathrm{L}^{-1} \cdot \mathrm{s}^{-1}$ (high $\Delta X \mathrm{rs}$ ) gave the most balanced result with the highest composite sensitivity and specificity (sensitivity 64\%, specificity $72 \%$ ) (fig. 4a). At $95 \%$ specificity, the corresponding $\Delta X \mathrm{rs}$ value was $0.26 \mathrm{kPa} \cdot \mathrm{L}^{-1} \cdot \mathrm{s}^{-1}$ (area under the curve (AUC) 0.70). The ROC curve constructed using FEV1 was almost identical with regards to sensitivity, specificity and AUC (fig. $4 \mathrm{~b}$ ). COPD patients with high $\triangle X \mathrm{rs}$ reported significantly higher mMRC score at all GOLD grades: $\mathrm{p}=0.002$ in GOLD 2, and $\mathrm{p}<0.001$ in GOLD 3 and 4 (fig. 5).

\section{Discussion}

The measurement of lung mechanics noninvasively during tidal breathing without the need to perform specific respiratory manoeuvres offers obvious clinical attractions. However, it has not been widely adopted in adult medicine due to uncertainties about the clinical utility and generalisability of these measurements. Our data confirm good between-test reproducibility of a range of oscillometric indices in a large COPD population and presents data about the degree of EFL during tidal breathing, measured over multiple breaths. Our measurements distinguished control subjects from those with COPD, worsened as lung mechanics became more impaired and identified individuals more likely to report significantly greater degree of breathlessness. These data have implications for how we interpret both oscillometric lung mechanics and symptom intensity in COPD.

TABLE 3 Spearman's rank correlation coefficient of reactance difference

\begin{tabular}{|c|c|c|c|c|}
\hline \multirow[t]{2}{*}{ Parameter } & \multicolumn{2}{|c|}{ COPD and controls ${ }^{\#}$} & \multicolumn{2}{|c|}{$\operatorname{COPD}^{\pi}$} \\
\hline & Correlation & p-value & Correlation & p-value \\
\hline Age years & 0.313 & $<0.001$ & 0.057 & NS \\
\hline Height cm & -0.145 & $<0.001$ & -0.150 & $<0.001$ \\
\hline Weight kg & 0.045 & NS & 0.171 & $<0.001$ \\
\hline Sex & 0.022 & NS & -0.039 & NS \\
\hline $\mathrm{BMI} \mathrm{kg} \cdot \mathrm{m}^{-2}$ & 0.138 & $<0.001$ & 0.289 & $<0.001$ \\
\hline Smoking $^{+}$pack-years & 0.234 & $<0.001$ & 0.076 & NS \\
\hline $\mathrm{PaO}_{2}^{+} \mathrm{kPa}$ & -0.452 & $<0.001$ & -0.260 & $<0.001$ \\
\hline 6MWD+ & & & 0.324 & $<0.001$ \\
\hline mMRC dyspnoea scale score ${ }^{+}$ & 0.530 & $<0.001$ & 0.362 & $<0.001$ \\
\hline SGRQ-C score $^{+}$ & 0.561 & $<0.001$ & 0.353 & $<0.001$ \\
\hline FEV1 L & -0.632 & $<0.001$ & -0.444 & $<0.001$ \\
\hline FEV $1 \%$ pred & -0.635 & $<0.001$ & -0.437 & $<0.001$ \\
\hline FVC L & -0.423 & $<0.001$ & -0.284 & $<0.001$ \\
\hline FEV $_{1} /$ FVC & -0.595 & $<0.001$ & -0.321 & $<0.001$ \\
\hline $\mathrm{IC}^{+} \mathrm{L}$ & -0.321 & $<0.001$ & -0.136 & $<0.001$ \\
\hline $\mathrm{RV}^{+} \mathrm{L}$ & 0.478 & $<0.001$ & 0.226 & $<0.001$ \\
\hline
\end{tabular}

p-values are one-tailed. COPD: chronic obstructive pulmonary disease; $\mathrm{BMI}$ : body mass index; $\mathrm{PaO}_{2}$ : arterial oxygen tension; 6MWD: 6-min walking distance; mMRC: modified Medical Research Council; SGRQ-C: St George's Respiratory Questionnaire for COPD patients; FEV1: forced expiratory volume in $1 \mathrm{~s}$; FVC: forced vital capacity; IC: inspiratory capacity; RV: residual volume; NS: nonsignificant. " $:$ n=654; ๆ: $n=425 ;{ }^{+}$: analysis restricted to patients with complete data. 

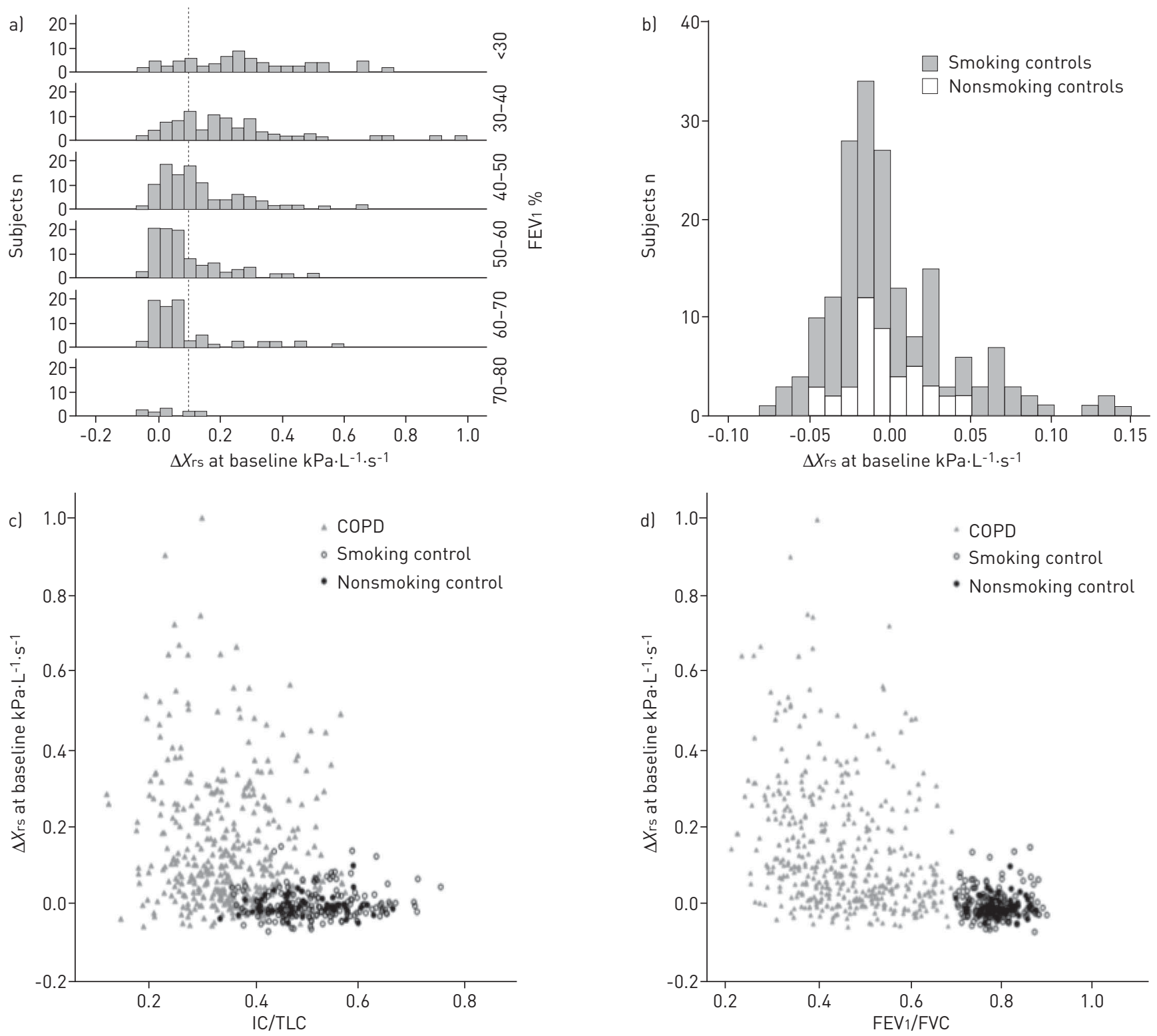

FIGURE 3 Distribution of reactance difference $\left(\Delta X_{\mathrm{rs}}\right)$ at baseline. Histograms displaying $\Delta X_{\mathrm{rs}}$ a) at different levels of airway obstruction in chronic obstructive pulmonary disease (COPD) patients, and b) in nonsmoking and smoking controls. Mean $\Delta X_{\mathrm{rs}}$ plotted against the c) inspiratory capacity (IC)/total lung capacity (TLC) and d) forced expiratory volume in $1 \mathrm{~s}$ (FEV1)/forced vital capacity (FVC) ratios.

Our analysis required us to partition inspiratory and expiratory lung mechanics. For most of our measurements, we only had mean inspiratory and expiratory data. However, in a subset of COPD patients, the breath-by-breath $\Delta X_{\mathrm{rs}}$ readings were retrieved and compared with our multiple-breath measurements. No systematic disagreements were observed between the two methods. Our approach differs from previous reports of data on tidal EFL where EFL has been defined on an individual-breath basis and where relatively few breaths have been recorded $[14,15]$. As is clear from inspection of previously published data $[14,15]$, the end-expiratory lung volume varies from breath to breath; hence, not all breaths will exhibit tidal flow limitation on all occasions $[15,26]$. A threshold $\Delta X \mathrm{rs}$ of $0.28 \mathrm{kPa} \cdot \mathrm{L}^{-1} \cdot \mathrm{s}^{-1}$ identifies EFL on individual breaths and can be used to determine whether a COPD patient is predominantly flow limited or not. Our data, however, represent a continuous spectrum, with the disadvantage that values beyond the critical threshold may not be linearly related to the total number of flow-limited breaths, but could be influenced by the effort involved in specific breaths. Nonetheless, we believe our data have utility, given their strong correlation with many clinical parameters.

The reproducibility of our resting impedance data was comparable to values reported previously for oscillometry averaging mechanics over the respiratory cycle. Our data showed comparable short-term 

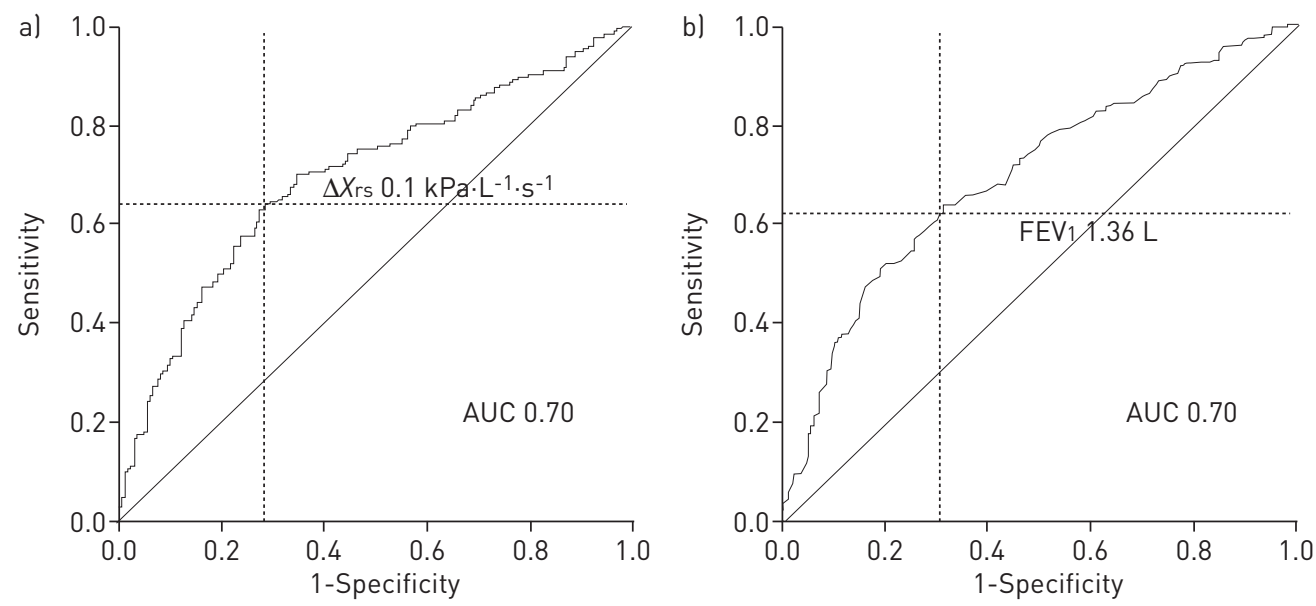

FIGURE 4 Receiver operating characteristic curves illustrating the performance of a) reactance difference $\left(\Delta X_{\mathrm{rs}}\right)$ and b) forced expiratory volume in $1 \mathrm{~s}\left(\mathrm{FEV}_{1}\right)$ in estimating presence of breathlessness in chronic obstructive pulmonary disease patients as the discrimination threshold is varied. AUC: area under the curve.

reproducibility for the $\mathrm{Rr}_{5}$ data irrespective of the phase of respiration in which it was measured [24]. High $\Delta X_{r s}$ values were essentially absent from healthy controls, with little variation between measurements. A previous study at our site found similar results in a healthy elderly population aged $>70$ years [27], while a study by DEBIssCHOP et al. [28] using the negative expiratory pressure technique reported that $32-38 \%$ of healthy elderly subjects ( $>80$ years) had flow-limited breaths. Though differences in entry criteria might partly explain this disagreement, multiple-breath measurements inevitably smooth the results. If a test subject is flow limited during one breath but not the following breath, the resulting mean over several breaths will lower the $\Delta X_{\text {rs }}$ to the point where it might fall under the detection level.

COPD patients with high $\Delta X_{\text {rs }}$ had more variation between measurements. This may be due to differing degrees of effort during tidal breathing on different occasions or changes in operating lung volume. Although the mean value varied, relatively few individuals moved from a value above our critical threshold to one below that value. We saw a progressive increase in median $\Delta X_{\mathrm{rs}}$ across GOLD grades driven by decreasing expiratory $R_{\mathrm{rs}_{5}}$ values, reflecting the impact of EFL $[14,15]$. Total reactance data in COPD was largely driven by change in the expiratory $R_{\mathrm{rs}_{5}}$ values. COPD patients had lower IC than controls, decreasing with increasing severity of disease (table 1), and a strong correlation was found between $\mathrm{Rrs}_{5}$ and IC (table 3). A previous study by DIAZ et al. [29] found reduced IC was predicted to separate clearly between EFL and non-EFL COPD patients. In our study, a considerable overlap was seen across a wide range of IC/ TLC and FEVı/FVC ratios (fig. $3 \mathrm{c}$ and d), but as a group, COPD patients with high $\triangle X_{\text {rs }}$ had lower IC/TLC ratio that those with low $\Delta X_{\text {rs }}$ measurements (fig. 3c). Obese subjects are known to experience flow-limited breaths [30], and as expected, a strong correlation was confirmed between $\Delta X_{\text {rs }}$ and BMI (table 3). The small number of controls with a high $\Delta X_{\text {rs }}$ in this study had significantly higher BMI. We suspect that a
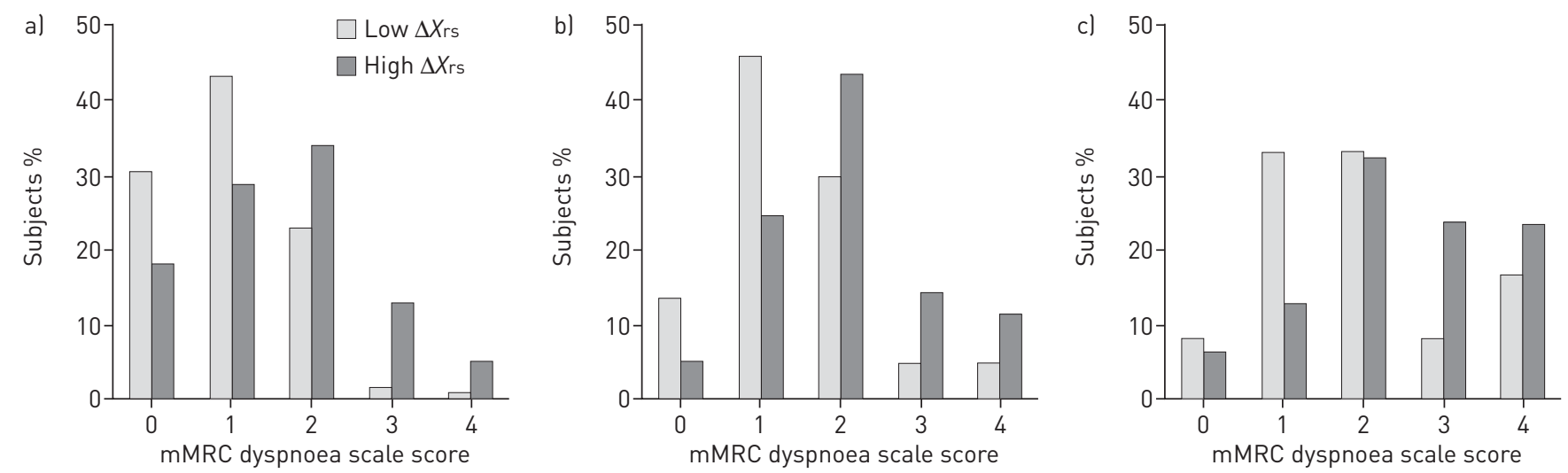

FIGURE 5 Distribution of the modified Medical Research Council (mMRC) dyspnoea scale score in Global Initiative for Chronic Obstructive Lung Disease grade a) 2 , b) 3 and c) 4 with low and high reactance difference $\left(\Delta X_{\mathrm{rs}}\right)$, defined by the threshold of $0.1 \mathrm{kPa} \cdot \mathrm{L}^{-1} \cdot \mathrm{s}^{-1}$. Low $\Delta X_{\mathrm{rs}}$ : a) $\left.\mathrm{n}=117, \mathrm{~b}\right) \mathrm{n}=80$ and c) $\mathrm{n}=12$; high $\Delta X$ rs: a) $n=38$, b) $n=96$ and c) $n=46$. 
considerable proportion of the abnormal $\Delta X \mathrm{rs}$ measurements found in controls with only moderate spirometric impairment could be attributed to flow-limited breaths in obese test subjects.

Taken together with the greater spontaneous variability in mean $\Delta X_{\mathrm{rs}}$ in COPD, these data suggest that end-expiratory lung volume is dynamically regulated, possibly to avoid persistent tidal EFL where possible. Further studies will be needed to understand the extent of this variability and the degree to which variation in abdominal muscle activity during expiration contributes to it.

Measuring reactance over multiple breaths retrieves information from a longer time span than breath-by-breath measurements, and aberrations in breathing pattern occurring within an individual breath are averaged over the entire measurement period, yielding a more stable measurement. Reactance spikes from EFL breaths in COPD patients increase the measurement, while in the healthy control group, a very low $\Delta X \mathrm{rs}$ was found.

Multiple-breath $\Delta X_{\mathrm{rs}}$ was similar to FEV1 in its ability to identify breathlessness, defined as having an $\mathrm{mMRC}$ score $\geqslant 2$, using ROC curve analysis (fig. 4). However, these data are, to a degree, complementary, as we found that COPD patients with high $\Delta X \mathrm{rs}$ reported significantly higher mMRC scores across all GOLD grades. Consequently, we suggest that $\Delta X \mathrm{rs}$ can be used as a marker for the subjective feeling of dyspnoea, adding information beyond spirometry on its own.

Our data have some limitations. EFL is a binary state whereas the mean value of $\Delta X \mathrm{rs}$ is a continuous variable reflecting both the number of flow-limited breaths recorded and the degree of reactance change across the breath. A clear understanding of the significance of the latter term is lacking. Our data may be considered as a way to define patients in whom flow limitation is likely to be present and who empirically fall beyond data seen in healthy subjects. Furthermore, detailed comparisons of the number of flow-limited breaths and their relationship to the mean $\Delta X$ rs would be helpful. Similarly, a measurement of IC made when the measurements were recorded would help track changes in end-expiratory lung volume, which could also contribute to between-day variability.

$\Delta X$ rs was close to zero in healthy controls, with little within- and between-day variability. COPD patients tended to have higher $\Delta X_{\mathrm{rs}}$ values than the controls and more variation between measurements. COPD patients with values exceeding those found in healthy individuals were prone to have higher mMRC scores at all GOLD grades. Measuring $\Delta X_{\mathrm{rs}}$ averaged over multiple breaths might increase the robustness of interpretation. In this setting, the previously applied threshold defining EFL only applies if all breaths are flow limited. The present study suggests that abnormal averaged multiple-breath $\Delta X \mathrm{rs}$ measurements should be regarded as pathological at values below the previously proposed detection level for EFL for individual breaths.

\section{Acknowledgements}

The authors thanks all participants of the study and members of Bergen Respiratory Research Group (Bergen, Norway) who took part in data collection, and give special thanks to our bioengineers Lene Svendsen, Rita Oppedal, Tina Endresen-Vinsjevik and Eli Nordeide (Haukeland University Hospital, Bergen, Norway) for performing/supervising the IOS and spirometry measurements.

\section{References}

1 Vestbo J, Hurd SS, Agusti AG, et al. Global strategy for the diagnosis, management, and prevention of chronic obstructive pulmonary disease: GOLD executive summary. Am J Respir Crit Care Med 2013; 187: 347-365.

2 Hyatt RE. The interrelationships of pressure, flow, and volume during various respiratory maneuvers in normal and emphysematous subjects. Am Rev Respir Dis 1961; 83: 676-683.

3 Tantucci C. Expiratory flow limitation definition, mechanisms, methods, and significance. Pulm Med 2013; 2013: 749860.

4 Calverley PM, Koulouris NG. Flow limitation and dynamic hyperinflation: key concepts in modern respiratory physiology. Eur Respir J 2005; 25: 186-199.

5 Grimby G, Stiksa J. Flow-volume curves and breathing patterns during exercise in patients with obstructive lung disease. Scand J Clin Lab Invest 1970; 25: 303-313.

6 Leaver DG, Pride NB. Flow-volume curves and expiratory pressures during exercise in patients with chronic airways obstruction. Scand J Respir Dis Suppl 1971; 77: 23-27.

7 O'Donnell DE, Webb KA, Bertley JC, et al. Mechanisms of relief of exertional breathlessness following unilateral bullectomy and lung volume reduction surgery in emphysema. Chest 1996; 110: 18-27.

8 O'Donnell DE, Sanii R, Anthonisen NR, et al. Effect of dynamic airway compression on breathing pattern and respiratory sensation in severe chronic obstructive pulmonary disease. Am Rev Respir Dis 1987; 135: 912-918.

9 Eltayara L, Becklake MR, Volta CA, et al. Relationship between chronic dyspnea and expiratory flow limitation in patients with chronic obstructive pulmonary disease. Am J Respir Crit Care Med 1996; 154: 1726-1734.

10 Koulouris NG, Kaltsakas G, Palamidas AF, et al. Methods for assessing expiratory flow limitation during tidal breathing in COPD patients. Pulm Med 2012; 2012: 234145.

11 Koulouris NG, Valta P, Lavoie A, et al. A simple method to detect expiratory flow limitation during spontaneous breathing. Eur Respir J 1995; 8: 306-313. 
12 Fry DL, Ebert RV, Stead WW, et al. The mechanics of pulmonary ventilation in normal subjects and in patients with emphysema. Am J Med 1954; 16: 80-97.

13 Mead J. Physical properties of human lungs measured during spontaneous respiration. J Appl Physiol 1953 1953; 5: 779-796.

14 Dellaca RL, Santus P, Aliverti A, et al. Detection of expiratory flow limitation in COPD using the forced oscillation technique. Eur Respir J 2004; 23: 232-240.

15 Dellaca RL, Duffy N, Pompilio PP, et al. Expiratory flow limitation detected by forced oscillation and negative expiratory pressure. Eur Respir J 2007; 29: 363-374.

16 Kelly VJ, Brown NJ, Sands SA, et al. Effect of airway smooth muscle tone on airway distensibility measured by the forced oscillation technique in adults with asthma. J Appl Physiol 2012; 112: 1494-1503.

17 Vestbo J, Anderson W, Coxson HO, et al. Evaluation of COPD longitudinally to identify predictive surrogate end-points (ECLIPSE). Eur Respir J 2008; 31: 869-873.

18 Crim C, Celli B, Edwards LD, et al. Respiratory system impedance with impulse oscillometry in healthy and COPD subjects: ECLIPSE baseline results. Respir Med 2011; 105: 1069-1078.

19 Meguro M, Barley EA, Spencer S, et al. Development and validation of an improved, COPD-specific version of the St. George Respiratory Questionnaire. Chest 2007; 132: 456-463.

20 ATS Committee on Proficiency Standards for Clinical Pulmonary Function Laboratories. ATS statement: guidelines for the six-minute walk test. Am J Respir Crit Care Med 2002; 166: 111-117.

21 Spruit MA, Polkey MI, Celli B, et al. Predicting outcomes from 6-minute walk distance in chronic obstructive pulmonary disease. J Am Med Dir Assoc 2012; 13: 291-297.

22 Gulsvik A, Tosteson T, Bakke P, et al. Expiratory and inspiratory forced vital capacity and one-second forced volume in asymptomatic never-smokers in Norway. Clin Physiol 2001; 21: 648-660.

23 Standardization of spirometry, 1994 update. American Thoracic Society. Am J Respir Crit Care Med 1995; 152 : $1107-1136$.

24 Oostveen E, MacLeod D, Lorino $\mathrm{H}$, et al. The forced oscillation technique in clinical practice: methodology, recommendations and future developments. Eur Respir J 2003; 22: 1026-1041.

25 Wanger J, Clausen JL, Coates A, et al. Standardisation of the measurement of lung volumes. Eur Respir J 2005; 26: 511-522.

26 Boni E, Corda L, Franchini D, et al. Volume effect and exertional dyspnoea after bronchodilator in patients with COPD with and without expiratory flow limitation at rest. Thorax 2002; 57: 528-532.

27 Aarli BB, Eagan TM, Ellingsen I, et al. Reference values for within-breath pulmonary impedance parameters in asymptomatic elderly. Clin Respir J 2013; 7: 245-252.

28 de Bisschop C, Marty ML, Tessier JF, et al. Expiratory flow limitation and obstruction in the elderly. Eur Respir J 2005; 26: 594-601.

29 Diaz O, Villafranca C, Ghezzo $\mathrm{H}$, et al. Role of inspiratory capacity on exercise tolerance in COPD patients with and without tidal expiratory flow limitation at rest. Eur Respir J 2000; 16: 269-275.

30 Pankow W, Podszus T, Gutheil T, et al. Expiratory flow limitation and intrinsic positive end-expiratory pressure in obesity. J Appl Physiol 1998; 85: 1236-1243. 